\title{
Comparison of right ventricular weight at necropsy in interstitial pulmonary fibrosis and in chronic bronchitis and emphysema
}

\author{
GE PACKE,* RM CAYTON, CW EDWARDS \\ From the Departments of * Respiratory Medicine and Histopathology, East Birmingham Hospital, Birmingham
}

SUMMARY The ventricular weights in 43 patients with interstitial pulmonary fibrosis were retrospectively compared with those in 172 patients with emphysema and chronic bronchitis. The mean I right ventricular weight of patients with interstitial pulmonary fibrosis and those with emphysema ${ }_{\circ}^{+}$ and chronic bronchitis was $85.5 \mathrm{~g}$ (SD 23.2$)$ and $88.8 \mathrm{~g}(34 \cdot 3)$, respectively. Thirty five patients ${ }^{\circ}$ $(81 \%)$ with interstitial pulmonary fibrosis had a right ventricular weight over $65 \mathrm{~g}$ compared with $\vec{C}_{\bar{C}}$ $124(72 \%)$ of those with emphysema. Fifty three per cent of both those with interstitial pulmonary fibrosis and those with chronic bronchitis and emphysema had a right ventricular weight greater than $80 \mathrm{~g}$. Differences between the two groups were not significant. These results suggest that the $\vec{\varrho}_{\infty}$ prevalence of right ventricular hypertrophy and pulmonary hypertension in interstitial pulmonary? fibrosis is similar to that found in chronic bronchitis and emphysema.

Cor pulmonale may be defined as "hypertrophy of the right ventricle resulting from diseases affecting the function and/or the structure of the lung, except when these pulmonary alterations are the result of diseases that primarily affect the left side of the heart or congenital heart disease". ${ }^{1}$ The prevalence of right ventricular hypertrophy in chronic pulmonary diseases is poorly documented, except in chronic bronchitis and emphysema, where a prevalence at necropsy of $34 \%$ has been reported. ${ }^{2}$ Cor pulmonale is also a late complication of interstitial pulmonary fibrosis, but in this condition its prevalence is unknown. The purpose of this study was to compare the prevalence of cor pulmonale in patients with chronic bronchitis and emphysema with that in patients with interstitial pulmonary fibrosis by measuring the ventricular weights at necropsy.

\section{Patients and methods}

The ventricular weights from 43 patients $(32 \mathrm{men})$ with interstitial pulmonary fibrosis were obtained from consecutive necropsy files covering 15 years at this hospital. The mean age of this group was 66 years (SD 8.5) range 45-87 years. These were compared with the ventricular weights of 172 patients (146 men) with chronic bronchitis and emphysema of mean age 70 years $(9 \cdot 0$; range $47-90$ years) who had died during the same period.

Ventricular weights were estimated by the method 3 of Fulton et al. ${ }^{3}$ Using this method, the left ventricle and septum are weighed together after removal of epicardial fat, and the free wall of the right ventricle is $\bar{O}$ weighed separately. The upper limit of normal for the weight of the left ventricle and septum $(\mathrm{LV}+\mathrm{S})$ is 3 . $190 \mathrm{~g}$, and for the right ventricle (RV), $65 \mathrm{~g}$. The normal range for the expression $L V+S / R V$ is between 3 2.3 and $3.3 \mathrm{~g}$. Some authorities consider that an $R V_{0}$ greater than $65 \mathrm{~g}$ indicates right ventricular hypertrophy, ${ }^{2}$ whereas others require a weight of $80 \mathrm{~g}$ or more. $^{3}$

Results

Of the patients with interstitial pulmonary fibrosis, $35 \mathrm{\omega}$ of $43(81 \%)$ had a right ventricle weighing $65 \mathrm{~g}$ or more compared with 124 of $172(72 \%)$ of the patients

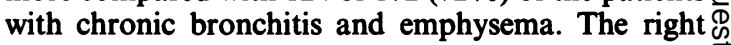
ventricle weighed $80 \mathrm{~g}$ or more in 23 of $43(53 \%){ }^{+}$ patients with interstitial pulmonary fibrosis and in $91 \frac{0}{\circ}$ of $172(53 \%)$ patients with chronic bronchitis and $\vec{\Phi}$ emphysema. The mean right ventricular weight for $\frac{\mathrm{P}}{\mathrm{D}}$ patients with interstitial pulmonary fibrosis was $85.5 \varrho$ (23.2) $\mathrm{g}$ and 88.8 (34.3) $\mathrm{g}$ for those with chronic bron 
chitis and emphysema. The corresponding weights for $\mathrm{LV}+\mathrm{S}$ were $171.0 \mathrm{~g}(37.8) \mathrm{g}$ and $189.6(59.9) \mathrm{g}$ for interstitial pulmonary fibrosis and chronic bronchitis and emphysema, respectively. The ratio $L V+S / R V$ was $2.13(0.63)$ in interstitial pulmonary fibrosis and $2.35(0.77)$ in patients with chronic bronchitis and emphysema. Differences between the two groups were not significant.

\section{Discussion}

In any study designed to estimate the prevalence of a condition its definition is of paramount importance. In the context of cor pulmonale it is interesting that while the WHO definition requires the demonstration of right ventricular hypertrophy, ${ }^{1}$ clinicians commonly await the appearance of oedema or overt right ventricular failure before diagnosing cor pulmonale in their patients. Although some pathologists define right ventricular hypertrophy as a right ventricular weight exceeding $65 \mathrm{~g},{ }^{2}$ others regard this figure as merely the upper limit of normal and do not consider unequivocal hypertrophy to be present unless the right ventricle weighs $80 \mathrm{~g}$ or more. ${ }^{3}$

Based on a right ventricle weight of $80 \mathrm{~g}$, this study indicates that right ventricular hypertrophy is present in $53 \%$ of patients with terminal interstitial pulmonary fibrosis, an identical figure to that found in chronic bronchitis and emphysema. As it has been shown that an increased right ventricle weight at necropsy indicates pulmonary hypertension during life ${ }^{4}$ our data suggest that at the time of death the prevalence of pulmonary hypertension in patients with interstitial pulmonary fibrosis is similar to that in patients with chronic bronchitis and emphysema.

Although the anatomical changes of hypoxic cor pulmonale associated with chronic bronchitis and emphysema have been well documented, ${ }^{4}$ there is little published data on the morphology of the pulmonary vasculature in interstitial pulmonary fibrosis. In one necropsy study seven cases were investigated, of which four showed unequivocal right ventricular hypertrophy, together with a thick muscular media and intimal longitudinal muscular proliferation in pulmonary arteries and arterioles. ${ }^{5}$ More severely affected vessels showed intimal fibrosis and recanalisation of thrombi or total fibrous obliteration. In some instances there was a plexus of thin walled vessels, possibly representing the pulmonarysystemic anastomoses shown radiographically by Turner-Warwick. $^{6}$ Muscular proliferation and fibrosis have been descibed by Dunnill, ${ }^{7}$ who also emphasised the common occurrence of thrombi without an obvious embolic source.
Predictions of pulmonary artery pressure from non-invasive physiological variables in patients with interstitial pulmonary fibrosis have been shown to be less accurate that those in chronic bronchitis and emphysema, ${ }^{8}$ suggesting that different mechanisms may be entailed. This hypothesis is supported by the work of Weitzenblum et al, ${ }^{9}$ who emphasise the dual roles of hypoxia and anatomical derangement by fibrosis in the development of pulmonary hypertension in patients with interstitial pulmonary fibrosis. A high proportion of patients dying with fibrosing alveolitis show hypertrophy of smooth muscle and hyperplasia of mucous glands in the larger bronchi, suggesting that in the later stages of the disease there is an obstructive element which could contribute to hypoxia. ${ }^{10}$ The relative importance of these factors is unknown.

This study has shown that cor pulmonale and pulmonary hypertension are equally prevalent in interstitial pulmonary fibrosis and chronic bronchitis and emphysema. Further haemodynamic and anatomical studies in patients with interstitial pulmonary fibrosis are necessary to investigate the pathogenesis of pulmonary hypertension and cor pulmonale in this disease.

\section{References}

${ }^{1}$ World Health Organisation. Chronic cor pulmonale. A report of the expert committee. Circulation 1963;27:594-615.

${ }^{2}$ Heath D, Brewer D, Hicken P. Cor Pulmonale in emphysema. Springfield: Charles C Thomas, 1968.

${ }^{3}$ Fulton RM, Hutchinson EC, Morgan Jones A. Ventricular weight in cardiac hypertrophy. Br Heart J 1952;14:413-20.

${ }^{4}$ Harris P, Heath D. The human pulmonary circulation. Edinburgh: Churchill Livingstone, 1977.

${ }^{5}$ Heath D, Gillund TD, Kay JM, Hawkins CF. Pulmonary vascular disease in honeycomb lung. Journal of Pathology and Bacteriology 1968;95:423-30.

${ }^{6}$ Turner-Warwick M. Precapillary systemic-pulmonary anastomoses. Thorax 1963;18:225-37.

${ }^{7}$ Dunnill MS. Pulmonary pathology. Edinburgh: Churchill Livingstone, 1982.

${ }^{8}$ Bishop JM, Cross KW. Use of other physiological variables to predict pulmonary arterial pressure in patients with chronic respiratory disease. Eur Heart $J$ 1981;2:509-17.

${ }^{9}$ Weitzenblum E, Ehrhart M, Rasaholinjanahary J, et al. Pulmonary haemodynamics in idiopathic pulmonary fibrosis and other interstitial pulmonary diseases. Respiration 1983;44:118-27.

${ }^{10}$ Edwards $\mathrm{CW}$, Carlile A. The larger bronchi in cryptogenic fibrosing alveolitis: a morphometric study. Thorax 1982; 37:828-33.

Requests for reprints to: Dr GE Packe, Department of Respiratory Physiology, East Birmingham Hospital, Birmingham B9 5ST, England. 